\title{
Is leaf or sheath antibiosis involved in the resistance of maize composite EPS12 to Sesamia nonagrioides?
}

\author{
A. Butrón, ${ }^{1}$ B. Ordás, P. Revilla, G. Sandoya, A. Ordás, R.A. Malvar \\ Misión Biológica de Galicia, Spanish Council for Scientific Research, Apartado 28, \\ 36080 Pontevedra, Spain
}

\begin{abstract}
The pink stem borer (PSB) (Sesamia nonagrioides Lefèbvre, 1827; Lepidoptera: Noctuidae) is the main insect pest of maize (Zea mays L., Poaceae) in the Mediterranean area. Maize varieties partially resistant to PSB have been identified, but few studies have documented the mechanisms of resistance involved. The objectives of this research were to study the levels of leaf and sheath antibiosis of a maize population, EPS12, and determine whether antibiosis improved over the selection process for less stalk tunneling. A hybrid check and two Bacillus thuringiensis (Bt) hybrids were also examined. Several bioassays were carried out in a control chamber to evaluate antibiosis of maize leaves and sheaths against PSB larvae. Leaf antibiosis was significantly higher for EPS12 than for the hybrid check and sheath antibiosis was low for all non-Bt hybrids studied. We conclude that leaf and sheath antibiosis was not significantly improved during the selection process. Future efforts should look for other possible mechanisms of resistance, such as stem rind antibiosis.
\end{abstract}

Résumé-La sésamie du maïs (PSB; Sesamia nonagrioides Lefèbvre, 1827; Lepidoptera : Noctuidae) est le principal insecte ravageur du maïs (Zea mays L., Poaceae) de la région méditerranéenne. Des variétés de maïs partiellement résistantes à la sésamie (PSB) ont été identifiées, bien que peu d'études aient abordé les mécanismes de résistance impliqués. Les objectifs de notre recherche consistent à étudier l'antibiose au niveau des feuilles et de la gaine d'une population de maïs EPS12 et de vérifier s'il y a amélioration de l'antibiose lorsque nous faisons une sélection pour diminuer le taux de perçage des tiges. Nous avons aussi testé un témoin commercial hybride et deux hybrides Bt (Bacillus thuringiensis). Nous avons procédé à plusieurs bioessais dans des chambres de culture contrôlées afin de vérifier l'antibiose des feuilles et des gaines de maïs aux larves de sésamie (PSB). L'antibiose des feuilles est significativement plus élevée chez EPS12 que chez le témoin commercial hybride et celle des gaines est faible chez toutes les variétés non Bt étudiées. En conclusion, le processus de sélection n'améliore pas significativement l'antibiose des feuilles et des gaines. Les études futures devraient rechercher d'autres mécanismes de résistance, tels que l'antibiose du cortex de la tige.

[Traduit par la Rédaction]

\section{Introduction}

The pink stem borer (PSB) (Sesamia nonagrioides Lefèbvre, 1827; Lepidoptera: Noctuidae) is the main pest of maize (Zea mays L., Poaceae) in the Mediterranean area (Cordero et al. 1998). Differences among maize varieties in resistance to PSB damage have been reported by Malvar et al. (1993), Cartea et al. (1994), and Butrón et al. (1999). Antibiosis, or resistance in the strict sense, is the ability of a plant to reduce the growth or development of an

Received 27 May 2004. Accepted 5 May 2005.

${ }^{1}$ Corresponding author

(e-mail: abutron@mbg.cesga.es). insect when it is feeding on the plant. In a controlled experiment or environment, the amount of insect feeding can be rated as antibiosis. However, to ensure that the effects observed are those of antibiosis, insect development must be taken into consideration. Ordás et al. (2002) concluded that although antibiosis of the maize pith plays a role in resistance under field conditions, other resistance mechanisms may be involved. The first PSB generation infests young plants, feeding on whorl leaves (Anglade 1961). The following generations feed on the stem and the ear. The pith of maize stalks is the main food source for mature PSB larvae. Eggs are deposited between the stem and the leaf sheath and the larvae feed on the sheath for $2-3$ weeks 
before boring into the stem (personal observations).

The development of $\mathrm{Bt}$ maize varieties (those having Bacillus thuringiensis genes) appeared to be the ultimate solution to control losses caused by many lepidopteran species. However, some studies have shown the ability of some insects to adapt to Bt toxins (Tabashnik 1994; Huang et al. 1999; Andow et al. 2000). The stacking (combining) of several resistance genes has been proposed as one of the means to delay insect adaptation (Gould 1998). This could be achieved by stacking $\mathrm{Bt}$ genes in PSB-resistant maize varieties.

The maize population EPS12 was selected from a PSB-resistant composite, EPS7, of four Spanish landraces (Malvar et al. 1993; Vales et al. 2001; Velasco et al. 2002). Although the mechanisms of resistance involved are unknown, a breeding program to select for stalk resistance to PSB was initiated from the population EPS12 and continued through three cycles of recurrent selection.

The objectives of this research were $(i)$ to study the level of antibiosis of the leaves and sheaths of the EPS12 maize population against PSB and (ii) to determine whether antibiosis improved over the selection process for less stalk tunneling.

\section{Materials and methods}

Plant material used in the bioassays was from the maize population EPS12, the three populations selected from it (EPS12C1, EPS12C2, and EPS12C3), a susceptible hybrid (INRA260), and two Bt hybrids developed by Monsanto (MEBT31 and MEBT470). EPS12 is a synthetic population obtained from EPS7 after three cycles of recurrent selection for high yield (Vales et al. 2001). PSB larvae were reared in the laboratory using Eizaguirre's methodology (1989).

Laboratory assays were conducted to determine the antibiosis of different maize genotypes against PSB attack. In two bioassays, PSB larvae were reared on maize leaves to simulate first-generation PSB feeding (maize whorl stage). For the other bioassays, the larvae were fed with the sheath of maize leaves to mimic feeding by the second and subsequent generations. All bioassays were performed with fresh maize material grown under field conditions (all planted 10 May 2002) to follow the natural changes in antibiosis with plant stage. To evaluate leaf antibiosis, the bioassays were initiated on 11 and 28 June 2002 at approximately V6 and V10 stages, respectively, and maintained until PSB larvae began pupation. For the evaluation of sheath antibiosis, the bioassays were started on 1 and 22 August 2002 at R1-R2 and R3-R4 stages, respectively, and neonate larvae were fed for 15 days. For each bioassay and maize genotype, 50 individual neonate larvae were weighed and arranged in two blocks in a control cabinet $\left(26{ }^{\circ} \mathrm{C}\right.$ and photoperiod of 14L:10D). Fresh plant material was provided every 3-4 days and larval masses and mortality were recorded every 4 days.

The log-rank statistic was used to compare survival distributions (Cantor 1997; Ordás et al. 2002). The statistic determined whether differences between survival functions of larvae reared on different maize genotypes were significant at a probability level of $P \leq 0.05$ (LIFETEST procedure of SAS (2000)). For larval mass and accumulated mortality at each recording date, means among varieties were compared by Fisher's protected LSD. Larval mass means were first adjusted to initial larval mass by analysis of covariance.

\section{Results}

The combined analysis of variance for mortality and mass of larvae fed on maize leaves or sheaths detected significant bioassay $\times$ variety interactions (data not shown), but these interactions were mostly due to changes in magnitude rather than changes in rank.

There were differences in survival among larvae fed on different maize genotypes because differences among log-rank values were significant (Table 1). The positive values for the log-rank statistic indicate that the number of dead larvae is higher than the number expected under the null hypothesis of equivalent survival distributions. The mortality of the larvae fed with Bt leaves and sheaths was significantly greater than that of larvae fed with the non-Bt varieties tested.

In both bioassays, the lethal effect of the $\mathrm{Bt}$ hybrid MEBT31 on PSB larvae was higher than that of MEBT470, and this difference increased with plant development (Table 1). The PSB neonate larvae died within 2 weeks when fed with Bt leaves, whereas it took more than a month to obtain $66 \%$ mortality on the conventional maize varieties (Table 2). On the other hand, neonate larvae did not completely die within 2 weeks 
Table 1. Values of the log-rank statistic for testing homogeneity of survival curves of Sesamia nonagrioides larvae fed with leaves and sheaths of seven Zea mays (maize) varieties in two bioassays.

\begin{tabular}{|c|c|c|c|c|}
\hline \multirow[b]{2}{*}{ Maize variety } & \multicolumn{2}{|c|}{ Leaves } & \multicolumn{2}{|c|}{ Sheaths } \\
\hline & Bioassay 1 & Bioassay 2 & Bioassay 1 & Bioassay 2 \\
\hline MEBT31 & $24.9 a$ & $35.4 a$ & $32.2 a$ & $35.4 a$ \\
\hline MEBT470 & $24.8 a$ & $33.8 b$ & $33.8 a$ & $31.0 b$ \\
\hline EPS12C3 & $0.5 b$ & $-11.0 c$ & $-10.1 b c$ & $-28.2 e$ \\
\hline EPS12C2 & $-13.1 c$ & $-17.8 c d$ & $-2.8 b$ & $-0.6 c$ \\
\hline EPS12C1 & $-10.3 b c$ & $-8.8 c$ & $-24.2 d$ & $-15.7 d$ \\
\hline EPS12 & $2.4 b$ & $-4.9 c$ & $-11.0 b c$ & $-6.5 c d$ \\
\hline INRA260 & $-29.2 d$ & $-26.7 d$ & $-17.8 c d$ & $-15.3 d$ \\
\hline
\end{tabular}

Note: In each column, values followed by the same letter do not differ at the 0.05 probability level.

Table 2. Means across bioassays for accumulated mortality (\%) among Sesamia nonagrioides larvae fed with leaves and sheaths from seven Zea mays (maize) varieties at consecutive recording periods (4-day intervals, P1-P9).

\begin{tabular}{lccccccccc}
\hline Maize variety & P1 & P2 & P3 & P4 & P5 & P6 & P7 & P8 & P9 \\
\hline MEBT31 & $64 a$ & $98 a$ & $100 a$ & $100 a$ & $100 a$ & $100 a$ & $100 a$ & $100 a$ & $100 a$ \\
MEBT470 & $46 a b$ & $93 a$ & $100 a$ & $100 a$ & $100 a$ & $100 a$ & $100 a$ & $100 a$ & $100 a$ \\
EPS12C3 & $14 b c$ & $31 b$ & $32 b$ & $36 b$ & $36 b c$ & $44 b$ & $61 b c$ & $76 b$ & $76 b$ \\
EPS12C2 & $4 c$ & $13 c d$ & $23 b c$ & $27 b c$ & $28 c d$ & $35 b$ & $44 d$ & $56 c$ & $56 c$ \\
EPS12C1 & $14 b c$ & $23 b c$ & $25 b c$ & $33 b$ & $35 b c$ & $38 b$ & $53 c d$ & $64 b c$ & $64 b c$ \\
EPS12 & $14 b c$ & $30 b$ & $33 b$ & $39 b$ & $40 b$ & $44 b$ & $66 b$ & $78 b$ & $78 b$ \\
INRA260 & $8 c$ & $10 d$ & $14 c$ & $18 c$ & $18 d$ & $19 c$ & $29 e$ & $36 d$ & $36 d$ \\
& & & & & & & & & \\
MEBT31 & $66 a$ & $88 a$ & $100 a$ & $100 a$ & & & & & \\
MEBT470 & $59 a$ & $89 a$ & $99 a$ & $99 a$ & & & & & \\
EPS12C3 & $6 b c$ & $11 c d$ & $16 d$ & $23 d$ & & & & & \\
EPS12C2 & $13 b$ & $28 b$ & $37 b$ & $55 b$ & & & & & \\
EPS12C1 & $1 c$ & $4 d$ & $20 c d$ & $25 d$ & & & & & \\
EPS12 & $9 b c$ & $15 c$ & $31 b c$ & $43 b c$ & & & & & \\
INRA260 & $8 b c$ & $9 c d$ & $16 c d$ & $31 c d$ & & & & & \\
\hline
\end{tabular}

Note: In each column, values followed by the same letter do not differ at the 0.05 probability level.

when fed with MEBT470 sheaths because accumulated mortality was $99 \%$.

Mortality of larvae reared on leaves of the EPS12 population was significantly different from that of larvae reared on leaves of the susceptible check (INRA260), but no significant difference was detected when larvae were reared on maize sheaths (Tables 1 and 2). There were significant differences in leaf and sheath antibiosis among selection cycles (EPS12, EPS12C1, EPS12C2, and EPS12C3); however, the selection process did not directionally change the antibiosis level.
There was no significant difference in larval mass between the selection cycles and the susceptible check when larvae were reared on leaf material (Table 3). For the sheath bioassays, larval mass differed between EPS12 and the susceptible check at P3 and P4, but there was no significant difference between the subsequent cycles of selection (EPS12C1, EPS12C2, and EPS12C3) and the susceptible check at any period (Table 4).

\section{Discussion}

The level of antibiosis of conventional maize 
Table 3. Mean mass (g) of Sesamia nonagrioides larvae reared on leaf tissues of seven Zea mays (maize) varieties, recorded at 4-day intervals (P1-P9).

\begin{tabular}{lccccccccc}
\hline Maize variety & P1 & P2 & P3 & P4 & P5 & P6 & P7 & P8 & P9 \\
\hline MEBT31 & $-0.005 b$ & $-0.013 b$ & - & - & - & - & - & - & - \\
MEBT470 & $-0.002 b$ & $-0.002 b$ & - & - & - & - & - & - & - \\
EPS12C3 & $0.012 a$ & $0.037 a$ & $0.071 a$ & $0.081 a$ & $0.093 a$ & $0.101 a$ & $0.124 a$ & $0.152 a$ & $0.159 a$ \\
EPS12C2 & $0.014 a$ & $0.037 a$ & $0.065 a$ & $0.083 a$ & $0.098 a$ & $0.099 a$ & $0.114 a$ & $0.145 a$ & $0.156 a$ \\
EPS12C1 & $0.012 a$ & $0.032 a$ & $0.061 a$ & $0.073 a$ & $0.085 a$ & $0.096 a$ & $0.109 a$ & $0.123 a$ & $0.136 a$ \\
EPS12 & $0.012 a$ & $0.036 a$ & $0.067 a$ & $0.089 a$ & $0.094 a$ & $0.105 a$ & $0.108 a$ & $0.135 a$ & $0.141 a$ \\
INRA260 & $0.015 a$ & $0.030 a$ & $0.060 a$ & $0.081 a$ & $0.091 a$ & $0.093 a$ & $0.115 a$ & $0.142 a$ & $0.159 a$ \\
\hline
\end{tabular}

Note: Mass was adjusted to the initial larval mass. In each column, means followed by the same letter do not differ at the 0.05 probability level.

Table 4. Mean mass (g) of Sesamia nonagrioides larvae reared on sheath tissues of seven Zea mays (maize) varieties, recorded at 4-day intervals (P1-P4).

\begin{tabular}{lllll}
\hline Maize variety & $\mathrm{P} 1$ & $\mathrm{P} 2$ & $\mathrm{P} 3$ & $\mathrm{P} 4$ \\
\hline MEBT31 & $0.002 c$ & $0.000 c$ & - & - \\
MEB470 & $0.002 c$ & $0.000 c$ & - & - \\
EPS12C3 & $0.022 a$ & $0.034 a$ & $0.081 a$ & $0.115 a$ \\
EPS12C2 & $0.020 a b$ & $0.030 a b$ & $0.070 a b$ & $0.108 a$ \\
EPS12C1 & $0.023 a$ & $0.032 a b$ & $0.072 a$ & $0.100 a b$ \\
EPS12 & $0.019 b$ & $0.029 b$ & $0.055 b$ & $0.079 b$ \\
INRA260 & $0.020 a b$ & $0.031 a b$ & $0.076 a$ & $0.112 a$ \\
\hline
\end{tabular}

Note: Mass was adjusted to the initial larval mass. In each column, means followed by the same letter do not differ at the 0.05 probability level.

was very low compared with that of Bt hybrids. All larvae fed with Bt leaves and $99.5 \%$ of larvae fed with Bt sheaths died within 2 weeks. Interestingly, González-Núñez et al. (2000) noted some differences in susceptibility to the B. thuringiensis Cry1Ab protein among four Spanish populations of PSB. Perhaps the EPS12 genes responsible for the partial resistance to PSB could be combined with $\mathrm{Bt}$ genes to further delay the development of $\mathrm{Bt}$ resistance among insect populations. The combination of the refuge strategy and high-dose toxin gene expression is intended to delay the development of Bt resistance but could be unsuccessful because its efficiency depends on a low frequency of recessive or partially recessive resistance alleles (Huang et al. 1999; Andow et al. 2000).

The population EPS12 showed a significantly higher level of leaf antibiosis than the susceptible check. Our results show that the selection made on EPS12 did not increase the mortality of larvae fed with leaf tissues because the log-rank statistic for the initial (EPS12) and final (EPS12C3) cycles did not differ. Guthrie et al. (1989) reported a lack of correspondence between resistance of maize to the first and second generations of the European corn borer (Ostrinia nubilalis Hübner; Lepidoptera: Crambidae). A similar lack of correspondence for PSB larvae could explain the absence of a change in leaf feeding damage (caused by the first generation) in response to selection for less stalk tunneling (caused by the second generation).

There were no significant differences among selection cycles in the mass of larvae reared on maize leaves. The higher mortality of larvae reared on EPS12, EPS12C1, EPS12C2, and EPS12C3 compared with those reared on INRA260 cannot be attributed solely to an anti-nutritional factor such as DIMBOA (2,4-dihydroxy-7-methoxy-1,4-benzoxazin-3-one) or other structural components that reduce quality or accessibility of nutrients (Gutiérrez and Castañera 1986; Coors 1987; Bergvinson et al. $1995)$ because there was no difference between 
the selection cycles and the INRA260 for larval mass.

The initial level of sheath antibiosis in EPS12 was low compared with that in the susceptible check because larval mass differed between the two varieties only in the third and fourth recording periods. For larval mortality, no significant difference was detected between the two varieties. The higher larval mortality and reduced mass observed on EPS12 compared with EPS12C3 suggested that some factors present in the EPS12 sheath affected larval mass and survival. Ordás et al. (2002) reported that some factors present in the pith of some maize inbreeds also affected PSB larval mass and survival. The changes in sheath antibiosis throughout the selection process for less stalk tunneling might be due to random drift or to an indirect selection response caused by negative correlations between different resistance mechanisms (Yan and Kang 2003). Finally, resistance mechanisms other than sheath antibiosis could be involved in the resistance of EPS12 to PSB. Among inbred lines resistant to stalk tunnelling, Ordás et al. (2002) detected significant differences in pith antibiosis and concluded that although pith antibiosis is involved in some stem resistance to $\mathrm{PSB}$, other undetermined mechanisms of resistance may play an important role in plant defence.

In conclusion, the maize population EPS12 showed variability in leaf and sheath antibiosis against PSB larvae, but this variability was not a factor for consideration during selection for less stalk tunneling. We conclude that antibiosis of the maize leaves and sheaths, although present, does not play a significant role in the resistance to stalk tunneling observed in EPS12, and future efforts should be devoted to investigating other possible mechanisms of resistance.

\section{Acknowledgments}

This research was funded by the Ministry of Education and Science (AGL2000-0944-C0201), Spain, and the Excma. Deputación Provincial de Pontevedra, Spain.

\section{References}

Andow, D.A., Olson, D.M., Hellmich, R.L., Alstad, D.N., and Hutchison, W.D. 2000. Frequency of resistance to Bacillus thuringiensis toxin Cry1 Ab in an Iowa population of European corn borer (Lepidoptera: Carbidae). Journal of Economic Entomology, 93: 26-30.
Anglade, P. 1961. Influence sur le rendement du maïs de l'infestation des tiges par la deuxième génération de la Sésamie (Sesamia nonagrioides Lef. Lép. Noctuidae). Méthodes de comparaison des hybrides par infestation artificielle. Annales des Epiphyties (Paris), 12: 357-372.

Bergvinson, D.J., Hamilton, R.I., and Arnason, J.T. 1995. Leaf profile of maize resistance factors to European maize borer, Ostrinia nubilalis. Journal of Chemical Ecology, 21: 343-354.

Butrón, A., Malvar, R.A., Cartea, M.E., Ordás, A., and Velasco, P. 1999. Resistance of maize inbreds to pink stem borer. Crop Science, 39: 102-107.

Cantor, A. 1997. Extending SAS survival analysis. Techniques for medical research. SAS Institute Inc., Cary, North Carolina.

Cartea, M.E., Malvar, R.A., Revilla, P., Ordás, A., and Álvarez, A. 1994. Seasonal occurrence and response of maize inbred lines to pink stem borer in the northwest of Spain. Maydica, 39: 191-196.

Coors, J.G. 1987. Resistance to the European corn borer, Ostrinia nubilalis (Hübner), in maize, Zea mays L., as affected by soil silica, plant silica, structural carbohydrates, and lignin. In Genetic aspects of plant mineral nutrition. Edited by H.W. Gabelman and B.C. Loughman. Martinus Nijhoff Publishers, Dordrecht, the Netherlands. pp. 445-456.

Cordero, A., Malvar, R.A., Butrón, A., Revilla, P., Velasco, P., and Ordás, A. 1998. Population dynamics and life-cycle of corn borers in south Atlantic European coast. Maydica, 43: 5-12.

Eizaguirre, M. 1989. Inducción de la diapausa en Sesamia nonagrioides Lef. (Lepidoptera: Noctuidae) y su papel en el ciclo biológico de las comarcas de Lérida. Ph.D. thesis, Polytechnic University of Catalonia, Spain.

González-Núñez, M., Ortego, F., and Castañera, P. 2000. Susceptibility of Spanish populations of the corn borers Sesamia nonagrioides (Lepidoptera: Noctuidae) and Ostrinia nubilalis (Lepidoptera: Crambidae) to a Bacillus thuringiensis endotoxin. Journal of Economic Entomology, 93: 459-463.

Gould, F. 1998. Sustainability of transgenic insecticidal cultivars: integrating pest genetics and ecology. Annual Review of Entomology, 43: 701-726.

Guthrie, W.D., Hawk, J.A., and Jarvis, J.L. 1989. Performance of maize inbred line DE811 in hybrid combinations: resistance to first and second generation European corn borers (Lepidoptera: Pyralidae). Journal of Economic Entomology, 82: 1804-1806.

Gutiérrez, C., and Castañera, P. 1986. Mecanismos bioquímicos de resistencia a los taladros. IV Jornadas Técnicas sobre Maíz, Lérida, Spain. pp. 47-61.

Huang, F., Buschman, L.L., Higgins, R.A., and McGaughey, W.H. 1999. Inheritance of resistance to Bacillus thuringiensis toxin (Dipel ES) in the 
European corn borer. Science (Washington, D.C.), 284: 965-967.

Malvar, R.A., Cartea, M.E., Revilla, P., Ordás, A., Álvarez, A., and Mansilla, J.P. 1993. Sources of resistance to pink stem borer and European corn borer in maize. Maydica, 38: 313-319.

Ordás, B., Butrón, A., Soengas, P., Ordás, A., and Malvar, R.A. 2002. Antibiosis of the pith maize to Sesamia nonagrioides (Lepidoptera: Noctuidae). Journal of Economic Entomology, 95: 1044-1048.

SAS Institute Inc. 2000. SAS/STAT ${ }^{\circledR}$. Version 8 [computer program]. SAS Institute Inc., Cary, North Carolina.

Tabashnik, B.E. 1994. Evolution of resistance to $B a$ cillus thuringiensis. Annual Review of Entomology, 39: 22-23.
Vales, M.I., Malvar, R.A., Revilla, P., and Ordás, A. 2001. Recurrent selection for grain yield in two Spanish maize synthetic populations. Crop Science, 41: 15-19.

Velasco, P., Revilla, P., Malvar, R.A., Butrón, A., and Ordás, A. 2002. Resistance to corn borers in crosses between sweet and field corn populations. Journal of the American Society for Horticultural Science, 127: 689-692.

Yan, W., and Kang, M.S. 2003. GGE biplot analysis: a graphical tool for breeders, geneticists, and agronomists. CRC Press, Boca Raton, Florida. 